\title{
Application of Human Settlement Science in Urban Planning
}

\author{
Fang Chen ${ }^{1,}$, , Jinglun Liu ${ }^{2, b}$ \\ ${ }^{1}$ chongqinng Normal University, Chongqing 400700, China \\ ${ }^{2}$ Baoshan University, Yunnan 678000, China \\ a49403591@qq.com, b121000679@qq.com
}

Keywords: Urban planning; Human habitat; Human settlements; the sciences of human settlements.

\begin{abstract}
The sciences of human settlements emphasizes to discuss the relation between human and environment in the holistic way. In this paper, we try to parse the sciences of human settlements in different levels. Through analyzing "whole thought" of the sciences of human settlements and problems of disassembling the object investigated in excess that currently exist at the Chinese urban planning work, the paper puts forward some suggestions that rebuild urban planning theory proceeding from whole thought, and change urban planning practice proceeding from achieving mastery through a comprehensive study of the subject. Especially the role that scientific content of living environment played to guide China's future urban planning. The Sciences of Human Settlements researches human habitat and discusses the relationship between people and environment. The purpose of it is to meet the requirements of human settlement and construct sustainable development pleasant good life environment. Although its spread and development no more than a decade, it has caused widespread resonance in the academic research and construction practice.
\end{abstract}

\section{The Connotation of the Human Settlement Science "whole thought"}

The sciences of human settlements is the science about the whole and integrity. It emphasizes that we should think about living environment starting from the overall and pursuit the overall interests of residential environment construction. Its connotation can be summarized as "whole thought".

From Concept to Explain. C.A.Doxiadis thinks that human settlement is "concentrated" in human life. Regardless of where, structure, how to form, its scale, level, their facilities and the contained material content, human life is human settlement according to the broad and even some fuzzy explanation. In short, residential environment is the place where we live in. This is an overall concept.

From Content Construction. "Living" is a broad concept, it not only means the housing itself, but contains almost all aspects of human life, including the material content such as the natural basis of human survival needs, physical space in human life and so on, including spirit level and social content that human and social factors act together. At the same time, it also involves the value orientation of relationship between human and environment. As C.A.Doxiadis pointed out, human settlement is "our life system". In order to study easily, people tend to divide the content of the residential environment constitution as to $\mathrm{Mr} \mathrm{Wu}$ Liangyong break it down to nature, human, society, house and support the five systems. But this is just a kind of research method, residential environment is an organic whole, the composition of its content complement each other and contact each other.

From the Hierarchy. The concept of hierarchy is an important content in living environment, residents and specific content is different in different living environment unit. Most importantly, there are huge differences in the complexity and development change. One of the main reasons caused problems of living environment is the shortage of unified understanding to the type and size of settlement and conceptual confusion often appears. At the same time, the modern living environment is a complete system especially with the thorough globalization process, the contact is more and more closely and mutual influence is more and more widely between different living environments. So far as to say that independent living environment element no longer exists in modern society, we live in a complete world habitat environment system. 
From the Subject Structure. The sciences of human settlements is based on "building, landscape, urban planning" as the core of the multidisciplinary group. Its peripheral disciplines are involved in geography, environment, ecology, philosophy, art, folklore, history, civil, psychology, society, economy, transportation and other fields, including all aspects of human society.

From the Thinking of Methodology. The sciences of human settlements is different from traditional multidisciplinary collaboration, it is not a general sense of interdisciplinary and edge discipline. It is less likely to develop into an independent discipline. It is a scientific theory that achieved mastery through a comprehensive subject matter connected with the living environment. Although its methodology system is still in the exploratory stage, the main methodological concept has been established, namely "melting penetration, comprehensive, integrated." Human settlement science advocators are known as the "melting penetration of comprehensive research method."

\section{The Current Problem of Urban Planning in our Country}

With the in-depth understanding of the city, humans explore the law of urban development and construction in an increasingly broad areas, the achievements are remarkable. But, why are the urban problems still serious? Why do humans still ragged in modern cities? There are objective reasons. The modern city is explosive growth characterized by high concentration and rapid expansion. But the subjective reason is more important. We often try to examine the modern city with old ideas, at last, city planning has many problems, such as way of thinking and research methods, and work organization and planning ways and the city problems are more and more serious.

Excessive Analytical Way of Thinking. At present, urban planning is still basically follow "investigation before planning, diagnosis before treatment" working mode in China. This kind of investigation, analysis, planning procedures have been widely adopted. This way of thinking is breaking things down and parse them one by one from a particular perspective. This way is effective to understand and analyze problem, but it is not the case to solve the problem. The reason is that man's ability to know things are limited, so we separate real things artificially for decomposition analysis. We are not able to grasp the internal relation fully and we are lack of the overall thinking of established things inner link. Meanwhile, the more complicated things, the deeper degree of decomposition analysis, gradually formed a vicious circle named" parse, parse and parse again, split, split and split again." The modern city is an open complex giant system, we still follow the traditional way of thinking in the urban planning, therefore, the understanding about each subsystem of city organic connection will be much more difficult and we can't really understand the cities' objective laws and city problem. At last, we will not be able to take the right action.

The Elaboration of Research Methods. The influence made by the traditional decomposition method and the simplified method thinking mode, the more people know the city, the more branch of discipline will produce. Now, the study of city are architecture, urban planning, geography, ecology, economics, sociology, political science, anthropology, etc. and will continue to develop with The Times. The result of multidispline is that each major often devote themselves to one side of the research question and focus on exploring the detailed rules and research all kinds of technical details. So, attending to one thing and losing another are inevitable. The results are often contradictory and don't have prospective and guidance.

The Excessive Specialization of Work Organization Way. The number of government departments involved in urban development and construction work increased greatly. Due to various reasons, all departments work is hard to reconcile. The realization of the urban development construction overall interests and long-term goals has been affected seriously.

The Excessive Technical Tendency of Planning Way. Now, the urban planning pay attention to reflect the development of the knowledge world and become a technology. But it ignores the life world and the meaning world. The rule of the pure technology will only make the city more materialistic, visual and superficial. We have lost the basic human humanistic spirit and abandoned the source of human philosophy spirit. It will not be able to reflect the basic requirement of human settlement life truly. 


\section{The Advice of the Sciences of Human Settlements in Urban Planning}

Focusing on the problem, modern city planning need to be guided by the overall view and strategic view. The characteristics of the sciences of human settlements comply with this requirement. Although the research of human settlement science in urban planning and construction has been widely used, not really enter into the development of the urban planning.

The Reconstruction of City Planning Theory. Each discipline have studied the planning of the city for a long time. It has a complete system. Now consider how to reconstruct the existing results judge from the situation of our country.

Building the urban planning system can help to construct a comprehensive city. Modern urban planning theory have two important aspects. The development of modern city system must adjust the thinking of the existing urban planning. It can achieve the overall interests. Dominated by comprehensive planning, it can form the theory of urban planning center system.

According to the requirement of the urban planning center theory system, strengthen the cooperation between each discipline, develop the related disciplines, it can form a wide range of basic theory system of urban planning.

The Improvement of Urban Planning Practice. Enhance the overall thinking ability, comprehensive coordination ability, dynamic strain capacity to solve the actual problem through a comprehensive study of the subject.

Learn some new methods in the understanding stage. In practice, to conduct a comprehensive investigation before the foundation of urban planning. Each component must include all aspects of the urban system. We must have insights, to consider the impact of all areas of urban planning. Multidisciplinary cooperation to survey, a variety of angles to investigate, a variety of methods to check, ensure the results of the survey is true and scientific.

Strengthen the degree of method in the analysis phase. We should analyze it before the start of the work. Choose a certain method .The choice must be wide. It should involve social science, natural science and engineering science. And the selected approach must be typical, practical and applicable. Then it can meet the needs of the urban planning analysis. Secondly, according to the actual requirements of planning objects, correct the selected approach. Especially correct the new research method which include different disciplines. So, only the analytical results can reflect the problem truly.

Strengthen the unity of the method in the problem solving phase. In the specific planning, according to the results to analysis. Strengthen the mix between different planning methods. Then we can realize the professional collaboration. Achieve the optimization of urban system components. Eventually we can form a complete city planning project. We can develop practical work according to "Survey - analysis - planning"

Strengthen the innovation of urban comprehensive management. Strengthen the management organizational structure, functional structure, and management mode and operation mechanism of the city. Establish and perfect a complete, scientific management system and the evaluation system of urban planning. Strengthen the legal and ethical management mechanism. Improve the coordinating abilities of the urban management.

The Main Ways and Means. With the unity of the meaning world and life world for guidance, we should come up with the guiding ideology and basic principles of urban planning according to the individual residents and social demand of the whole city. We have two ways to realize the goal. Strengthen the public and social participation. Establish and perfect the evaluation system of urban planning. The public and the society participation is an important approach to reflect the social needs. With the development of our country, the participation of social organizations and groups is more and more widely. And it play an important role. Urban planning evaluation is not only a form of public and social participation, but also a way of strengthening multidisciplinary. Can solve the problem of harmony and unity well. The evaluation of urban planning practice work has been very rich, we only need perfect evaluation of depth, effectiveness and scientific. The theory evaluation is a new topic 
and very difficult. But if you can solve the problem of interoperability and make it through urban planning theory development construction process, will have important positive impact.

Strengthen the training of new urban planning workers. Urban planning workers should strengthen the cultivation of the philosophy spirit and the exercise of thinking mode from the perspective of overall thinking demands. They should transform its traditional mode of scientific thinking, cultivate the overall concept, system, strategy and innovative spirit, and improve the ability of using integral or system method to handle problems.

The innovation of urban planning education. China's existing urban planning professional disciplines background mainly can be classified into four categories: architecture, engineer, science and forestry. They are mainly aimed at a certain aspects to realize the urban planning education. So they can't meet the requirements of the overall, system and science. If the urban planning education model has the characteristics of openness, inclusiveness and comprehensive, this not only conform the requirements of The Times, is also the development trend of the urban planning education.

Be practical and realistic to develop the local urban planning system. The sciences of human settlements should pay attention to reality based on various areas in urban planning application and choose the right breakthrough point. So he may have the satisfactory results.

\section{Conclusion}

We should stress the overall thinking, pursuit macro purpose, take into account the comprehensive, open, inclusive and dispersed network system in future urban planning system of China. Its basic content spread in all disciplines related to the city and form a comprehensive integrated urban planning center. The sciences of human settlements may not be the only way to achieve this goal, but it is a valuable exploration and a meaningful beginning.

\section{References}

[1] Wu Liangyong. Introduction to the sciences of human settlements[M].Beijing:China building industry press, 2001.

[2] Zou Deci. recognize the urban and rural planning from the height of the human settlement science [J]. urban planning 2002, 26(7): p. 9-10. 